\title{
Expression of prolactin-releasing peptide and prolactin in the euryhaline mudskippers (Periophthalmus modestus): prolactin-releasing peptide as a primary regulator of prolactin
}

\author{
T Sakamoto ${ }^{1,2}$, M Amano ${ }^{3}$, S Hyodo ${ }^{4}$, S Moriyama ${ }^{3}$, A Takahashi $^{3}$, H Kawauchi $^{3}$ and \\ M Ando' \\ ${ }^{1}$ Ushimado Marine Laboratory, Faculty of Science, Okayama University, Ushimado, Setouchi 701-4303, Japan \\ ${ }^{2}$ Faculty of Integrated Arts and Sciences, Hiroshima University, Kagamiyama, Higashi-Hiroshima 739-8521, Japan \\ ${ }^{3}$ School of Fisheries Sciences, Kitasato University, Sanriku, Ofunato 022-0101, Japan \\ ${ }^{4}$ Ocean Research Institute, University of Tokyo, Nakano, Tokyo 164-8639, Japan \\ (Requests for offprints should be addressed to T Sakamoto, Ushimado Marine Laboratory, Faculty of Science, Okayama University 130-17, Kashino, Ushimado, Setouchi, \\ 701-4303, Japan; Email: ryu @uml.okayama-u.ac.jp)
}

\begin{abstract}
Prolactin (PRL)-releasing peptide (PrRP) is a strong candidate stimulator of pituitary PRL transcription and secretion in teleosts. However, the role in control of extrapituitary PRL expression is unclear even in mammals. To study the possible presence of PrRP-PRL axes not only in the brain-pituitary but also in peripheral organs, the expression patterns of PrRP, PRL and growth hormone $(\mathrm{GH})$ were characterized in amphibious euryhaline mudskippers (Periophthalmus modestus). PrRP mRNA is abundantly expressed not only in the brain but also in the liver, gut and ovary, while less abundant expression was also detected in the skin and kidney. Corresponding to the distribution of PrRP mRNA, PRL mRNA was also detectable in these organs. During adaptation to different environments, the changes in mRNA levels of PrRP paralleled those in PRL in the brain-pituitary, liver and gut in an organ-specific manner. Brain PrRP mRNA and the pituitary PRL mRNA increased under freshwater and terrestrial conditions $(P<0.05)$; expression of PrRP and PRL in the gut of freshwater fish was higher $(P<0.05)$ than those in sea-water fish although there were no changes in fish kept out of water; no significant change was seen in the liver. Expressions of GH were not correlated with PrRP. In the gut, PrRP and PRL appear to be co-localized in the mucosal layer, especially in the mucous cells. Thus, PrRP may also be a local modulator of extrapituitary PRL expression and the PrRP-PRL axes in various organs may play an organ-specific role during environmental adaptation.
\end{abstract}

Journal of Molecular Endocrinology (2005) 34, 825-834

\section{Introduction}

Although prolactin (PRL) is historically known as a pituitary hormone; however, in the past few years, interest has been raised in locally produced, extrapituitary PRL. The current view of the regulation of pituitary PRL expression integrates a wide spectrum of molecules. However, the control of extrapituitary PRL expression is still poorly understood, both at the transcriptional and at the secretory levels (Goffin et al. 2002). Since extrapituitary PRL expression in trout, goldfish and seabream has been reported to be relatively high, unlike that in tetrapods (Santos et al. 1999, Yang et al. 1999, Imaoka et al. 2000), studies using aquatic teleosts should shed new light on the regulation of extrapituitary PRL in terrestrial vertebrates.

PRL-releasing peptide (PrRP) is a peptide identified from mammalian hypothalamus with a specific PRL- releasing activity on pituitary cells (Hinuma et al. 1998, Sakamoto et al. 2003a). Concurrently, Fujimoto et al. (1998) isolated a homologue of PrRP from the Japanese crucian carp, Carassius auratus langsdorfi. Recently, homologues have also been isolated from tilapia and chum salmon, showing these peptides to be identical to the carp peptide (Moriyama et al. 2002, Seale et al. 2002). Although there are contradictory data on PRL-releasing effects in rats, PrRP appears to be a potent hypothalamic secretagogue for PRL as well as an inducer of PRL transcription in teleost pituitaries (Sakamoto et al. 2003a). On the other hand, both in fish and in mammals, PrRP appears to inhibit secretion of growth hormone (GH; Sakamoto et al. 2003a), another member of the hormone family sharing a common ancestral gene with PRL (Rand-Weaver et al. 1993). In mammals, PrRP is expressed in the central nervous system, but is also produced in the digestive tract, kidney, pancreas, 
adrenal gland, gonads and decidua (Fujii et al. 1999). Although PrRP is suggested to be a local stimulator of decidual PRL release in humans (Reis et al. 2002), the tissue distribution of PrRP in non-mammalian species is unknown.

In teleosts, the most prominent action of PRL is osmoregulation in fresh water. Among a number of activities associated with PRL through vertebrates, such osmoregulatory actions are considered by some to be the common and primary action of PRL throughout the vertebrates (Hirano 1986). For example, PRL caused several amphibians to move to an aquatic habitat (Warburg 1995). Mudskipper fishes (Perciformes; Gobioidei) are amphibious and euryhaline: they spend the greater parts of their lives out of water, and also maintain osmotic balance in hypotonic fresh water as well as in hypertonic sea water. Therefore, they provide a unique model for studies on osmoregulatory action of PRL under both terrestrial and aquatic conditions, and may be an evolutionary link between terrestrial and aquatic vertebrates for the existence of an extrapituitary PrRP-PRL axis.

Against this background, we thought that the analyses of expression profiles of PrRP and PRL in the various organs during adaptation of the mudskipper to different osmotic environments would give a clue to the relationships between PrRP and PRL. In the present study, we show the tissue distribution of mRNAs for mudskipper PrRP, PRL and GH, as well as the changes in their levels during the terrestrial adaptation and adaptation to different salinities by Northern blotting. In addition, we examined the cellular localization of immunoreactive PrRP and PRL mRNA in the intestine, an osmoregulatory organ, to ascertain the morphological basis for the innervation.

\section{Materials and methods}

\section{Animals}

Adult mudskippers (Periophthalmus modestus) of both sexes weighing 4-6g were obtained from the estuary of the Fujii River that pours into the Inland Sea of Seto. The fish were kept in the laboratory in tanks of isotonic one-third sea water $\left(22-25^{\circ} \mathrm{C}\right.$ ) for more than 1 week (Sakamoto et al. 2000a). A small plate floated in each tank so that the animals could climb onto this plate ad libitum. Freshly excised tissues for RNA extraction were immediately frozen in liquid nitrogen and then stored at $-80{ }^{\circ} \mathrm{C}$.

\section{Experimental protocol}

The fishes were transferred from one-third sea water to either one-third sea water (control), fresh water $(0$ parts per thousand $(\mathrm{ppt}))$, sea water $(30 \mathrm{ppt})$ or to aquaria without water ( $n=4-6$ per group). Fishes transferred to one-third sea water, fresh water, or sea water were sampled after $10 \mathrm{~h}$ and 1 week. Since previous studies reported that many physiological changes occurred approximately $10 \mathrm{~h}$ after water deprivation when fishes lose water to a $20 \%$ reduction of initial body mass (Gordon et al. 1978, Lee \& Ip 1987, Sakamoto et al. 2002), the water-deprived fishes were sampled at this time point. This transfer study protocol was repeated three times and representative results are shown.

After quick blood collection by syringe from the hemal arch in the region of the caudal peduncle, the brain, pituitary, liver and gut were immediately removed, frozen in liquid nitrogen and then kept at $-80{ }^{\circ} \mathrm{C}$. The plasma was stored at $-40{ }^{\circ} \mathrm{C}$ after centrifugation. To avoid stress, fish were anaesthetized with tricaine methane sulfonate before handling. All fish were kept, handled and used in accordance with Guidelines for Animal Experimentation of Okayama University.

\section{RNA extraction}

Total RNA was extracted from pituitaries by the method of Chomczynski \& Sacchi (1987) using an RNA purification kit (Isogen; Wako Chemical, Osaka, Japan). Poly $(\mathrm{A})^{+}$RNA was obtained from other tissues by oligo(dT)-Sepharose chromatography using a Microprep RNA kit (Pharmacia) according to the manufacturer's protocol. Each set of tissue samples was extracted at the same time to avoid procedure variability among the groups. The RNA was quantified by spectrophotometry.

\section{PrRP cDNA probe}

First-strand cDNA was reverse-transcribed from brain poly $(\mathrm{A})^{+}$RNA using the First Strand cDNA Synthesis kit (Pharmacia Biotech, Uppsala, Sweden). Following the manufacturer's protocol, the primer 5'-GACCACGCG TATCGATGTCGACT $18^{-} \mathbf{3}^{\prime}$ was used for reverse transcription. One degenerate sense primer $\left(5^{\prime}-\mathrm{GA}(\mathrm{TC})\right.$ CG(AG)TTCTGGTA(CT)GTGG-3') designed based on the conserved regions of PrRPs, and an anchor primer (5'-GACGACGCGTATCGATGTCGAC-3') were used to clone the $3^{\prime}$ partial region of mudskipper PrRP cDNA.

During PCR, the $50 \mu \mathrm{l}$ reaction mixture $(1 \mu \mathrm{l}$ first-strand cDNA, $0 \cdot 4 \mu \mathrm{M}$ each sense and anchor primer, $0.2 \mathrm{mM}$ nucleotide mix and $5 \mu \mathrm{l} 10 \times \mathrm{PCR}$ buffer (final concentration, $10 \mathrm{mM}$ Tris/ $\mathrm{HCl}, \mathrm{pH} 8 \cdot 8$, $50 \mathrm{mM} \mathrm{KCl}, 2.5 \mathrm{mM} \mathrm{MgCl} 2,1.5$ units Gold-Taq DNA polymerase; PE Applied Biosystems, Chiba, Japan)) was subjected to 50 cycles of amplification. After activation of $\mathrm{Taq}$ polymerase at $95^{\circ} \mathrm{C}$ for $10 \mathrm{~min}$, each cycle 
consisted of a 1-min denaturation at $96{ }^{\circ} \mathrm{C}, 30$-s primer annealing at $52{ }^{\circ} \mathrm{C}$ and 1 -min primer extension at $73{ }^{\circ} \mathrm{C}$. The final extension was $7 \mathrm{~min}$ at $72{ }^{\circ} \mathrm{C}$.

A PCR-amplified cDNA product of expected size (363 bp) was observed after agarose gel electrophoresis (visualized by ethidium bromide staining). The DNA was extracted from the gels and ligated into pT7 Blue T-Vector (Novagen, Madison, WI, USA). Nucleotide sequencing of both strands was performed using an ABI DNA Sequencer 373 (Perkin-Elmer, Foster, CA, USA). Multiple clones were examined.

This partial sequence was identified as a PrRP cDNA fragment, because the optimized alignment of the corresponding regions of PrRP obtained from teleosts (Fujimoto et al. 1998, Moriyama et al. 2002, Seale et al. 2002) revealed $70 \%$ among the sequences, the topologies of the phylogenic trees of the aligned sequences were in accordance with the known phylogeny of teleosts (Clustal method) and the sequence did not match significantly other sequences deposited in the databases. The partial nucleotide and derived amino acid sequences of mudskipper PrRP are available from the GenBank nucleotide sequence database under accession no. AB089193.

\section{cDNA probes for $\mathrm{GH}$ and PRL}

First-strand cDNA was reverse-transcribed from pituitary RNA using the First Strand cDNA Synthesis kit with the NotI-d(T) $)_{18}$ primer (Pharmacia). Degenerate sense and antisense primers were synthesized based on the most conserved regions of the sequence of known teleost PRLs or GHs to clone the internal region of mudskipper cDNAs encoding PRL and GH. During PCR of the first-strand cDNA, primers for PRL (5'-GACAA(AG)CT(GT)GAGTG(ACT)CTCAG (ACTG)-3' (sense) and 5'-GCGGGGCA(AGGT)C(GT) (ACG)AG(GA)AC(CT)TT(CG)AGGAA-3' (antisense)) or GH (5'-CC(ACGT)AT(ACT)GA(CT)AA(AG)CA (CT)GA-3'(sense) and 5'-TC(AGTC)AC(TC)TT(AG) TGCAT(AG)TC-3' (antisense)), and KOD-Dash DNA polymerase (Toyobo, Osaka, Japan), in a $50 \mu$ reaction mixture, were subjected to 30 cycles of amplification. Each cycle consisted of $1 \mathrm{~min}$ at $94^{\circ} \mathrm{C}, 30 \mathrm{~s}$ at $54^{\circ} \mathrm{C}$ and $90 \mathrm{~s}$ at $74^{\circ} \mathrm{C}$. PCR products of the expected size (497 bp for PRL or $314 \mathrm{bp}$ for $\mathrm{GH}$ ), which correspond to amino acid residues $40-205$ of tilapia $\mathrm{PRL}_{188}$ or $61-167$ of bonito GH (Rand-Weaver et al. 1993), were seen after agarose gel electrophoresis. The DNA was extracted from the gels and ligated into pT7 Blue T-Vector (Novagen). Nucleotide sequencing of both strands was performed using an ABI DNA Sequencer 373 (Perkin-Elmer). Multiple clones were examined. These sequences were identified as target cDNAs also based on the alignment of the perciform cDNAs (Rand-Weaver et al. 1993). The sequences of PRL and GH are available from the GenBank nucleotide sequence database under accession nos. AB089194 and AB089195, respectively.

\section{Northern blot analyses}

The above mudskipper probes and cDNA of glyceraldehyde-3-phosphate dehydrogenase (GAPDH) were labeled with $\left[\alpha^{-32} \mathrm{P}\right] \mathrm{dCTP}$ (random priming, BcaBEST DNA labeling kit; Takara, Otsu, Japan). Total RNA $(2 \mu \mathrm{g})$ of the pituitary or poly(A) ${ }^{+}$RNA $(5 \mu \mathrm{g})$ of other tissues were size fractionated through a $1 \%$ agarose-formaldehyde gel and transferred onto a nylon membrane (Amersham) by capillary blotting (Sambrook et al. 1989). The RNA was covalently attached to the membane by baking at $80^{\circ} \mathrm{C}$ for $2 \mathrm{~h}$ and by UV cross-linking. The membranes were hybridized with the probe for PrRP, PRL, GH or GAPDH for $18 \mathrm{~h}$ following prehybridization in Perfecthyb hybridization solution (Stratagene) according to the manufacturer's instructions. The membranes were washed in $2 \times \mathrm{SSC}$ and $0 \cdot 1 \%$ SDS at $65{ }^{\circ} \mathrm{C}$ for $2 \times 10 \mathrm{~min}$. They were washed again with $1 \times \mathrm{SSC}$ containing $0 \cdot 1 \%$ SDS at $65^{\circ} \mathrm{C}$ for $20 \mathrm{~min}, 0 \cdot 1 \times \mathrm{SSC}$ containing $0 \cdot 1 \% \mathrm{SDS}$ for $2 \times 20 \mathrm{~min}$ at $65^{\circ} \mathrm{C}$, and then rinsed at room tmperature. The membranes were exposed to phosphorimaging plate (Fuji imaging plate, Bas III; Fuji Film, Tokyo, Japan). Intensity of the hybridization signals was assessed with an Auto Image Analyser (Bas 2000; Fuji Film). After analysis of one of the messages, the membranes were dehybridized as described by the manufacturer followed by autoradiographies to check that the probes were removed. The membranes were then rehybridized to the other probes sequentially. Serial dilutions of the RNA demonstated linearity between hybridization signals and serial dilutions (results not shown). mRNA data are represented in arbitrary units normalized to the quantity of GAPDH signals, which were relatively constant, and pooled RNA was used as an internal standard to adjust the variability among the blots. Molecular sizes were estimated relative to migration of a RNA size marker (Toyobo).

\section{PrRP-PRL localization in the gut}

The mudskippers were kept in fresh water for 7 days $(n=4)$, and the gut was fixed overnight in $4 \%$ paraformaldehyde in $0.1 \mathrm{M}$ phosphate-buffer fixative $(\mathrm{pH} 7 \cdot 4)$ at $4{ }^{\circ} \mathrm{C}$. The anterior part of the intestine, where PrRP and PRL expression was abundant, as shown by Northern blots (results not shown), was dehydrated in ethanol and embedded in paraplast (Monoject; Sherwood Medical, St Louis, MO, USA). In the mudskipper, the oesophagus is connected directly to the proximal intestinal swelling. Two sagittal serial sections $(5 \mu \mathrm{m}$ on a microtome $)$ were mounted 
separately on 3-aminopropyltriethoxysilane-coated slides.

Immunocytochemical staining of PrRP was carried out with anti-synthetic $\mathrm{C}$-RFa serum using a Histofine immunostaining kit (Nichirei, Tokyo, Japan) basically as described by Moriyama et al. (2002). Anti-synthetic C-RFa serum was diluted 1:5000 with $0 \cdot 1 \mathrm{M}$ phosphate buffer $(\mathrm{pH} 7 \cdot 4)$ containing $0.75 \% \mathrm{NaCl}$ and $0 \cdot 3 \%$ Triton X-100. To test the specificity of the immunoreaction, the adjacent sections were incubated with anti-synthetic $\mathrm{C}-\mathrm{RFa}$ serum that was preabsorbed overnight at $4{ }^{\circ} \mathrm{C}$ with excess synthetic $\mathrm{C}-\mathrm{RFa}(1 \mu \mathrm{g}$ peptide in $1 \mathrm{ml}$ antiserum).

For in situ hybridization of PRL mRNA, the fluoroscein-labelled oligonucleotide probe against mudskipper PRL (5'-GACACTTGGAGAGGGTGGTCTT TGTG AGTAGGACGTTGCAGATTGGACG(FITCdT)(FITC-dT)(FITC-dT)-FITC-3') was synthesized commercially (Amersham Pharmacia Biotech, Tokyo, Japan). Hybridization and washes were performed in the dark according to Hyodo \& Urano (1991). In brief, following prehybridization for $1 \mathrm{~h}$, hybridization was carried out at $37^{\circ} \mathrm{C}$ for $16 \mathrm{~h}$ with $500 \mathrm{ng} / \mathrm{ml}$ probe disolved in the hybridization medium containing $20 \mathrm{mM}$ Tris/HCl (pH 7.5), $6 \mathrm{mM}$ EDTA, 0.6 M NaCl, $10 \%$ dextran sulfate, $1 \times$ Denhardt's solution, $0.5 \mathrm{mg} / \mathrm{ml}$ calf thymus DNA and 40\% deionized formamide. The slides were washed at a final stringency of $30 \%$ formamide/ $1 \times \mathrm{SSC}$ at $37^{\circ} \mathrm{C}$. Control slides for specificity were hybridized with excess (4000-fold) unlabelled probe. The sections were mounted in Gel/Mount (Biomedia, Foster, CA, USA) and observed using a fluorescence microscope (EFD2 with $\mathrm{Hg} 100 \mathrm{~W}$ light source; Nikon, Tokyo, Japan) equipped with a chilled CGD camera (C5985; $756 \times 483 \times 8$ bit; Hamamatsu Photonics, Hamamatsu, Japan).

\section{Plasma ion analyses}

Plasma $\mathrm{Na}^{+}$(an indicator of plasma osmolality) was determined by atomic absorption spectrophotometry (Z5300; Hitachi, Tokyo, Japan).

\section{Statistics}

All data are presented as means \pm S.E.M. Statistical significance of differences among mean values was tested using an ANOVA followed by the least significant difference test with Statview 4.11 (Abacus Concepts).

\section{Results}

\section{Tissue distribution of PrRP, PRL and GH mRNAs}

Transcripts of PrRP at about 1.7 and/or $3 \mathrm{~kb}$ were abundantly expressed in the brain, liver, gut and ovary
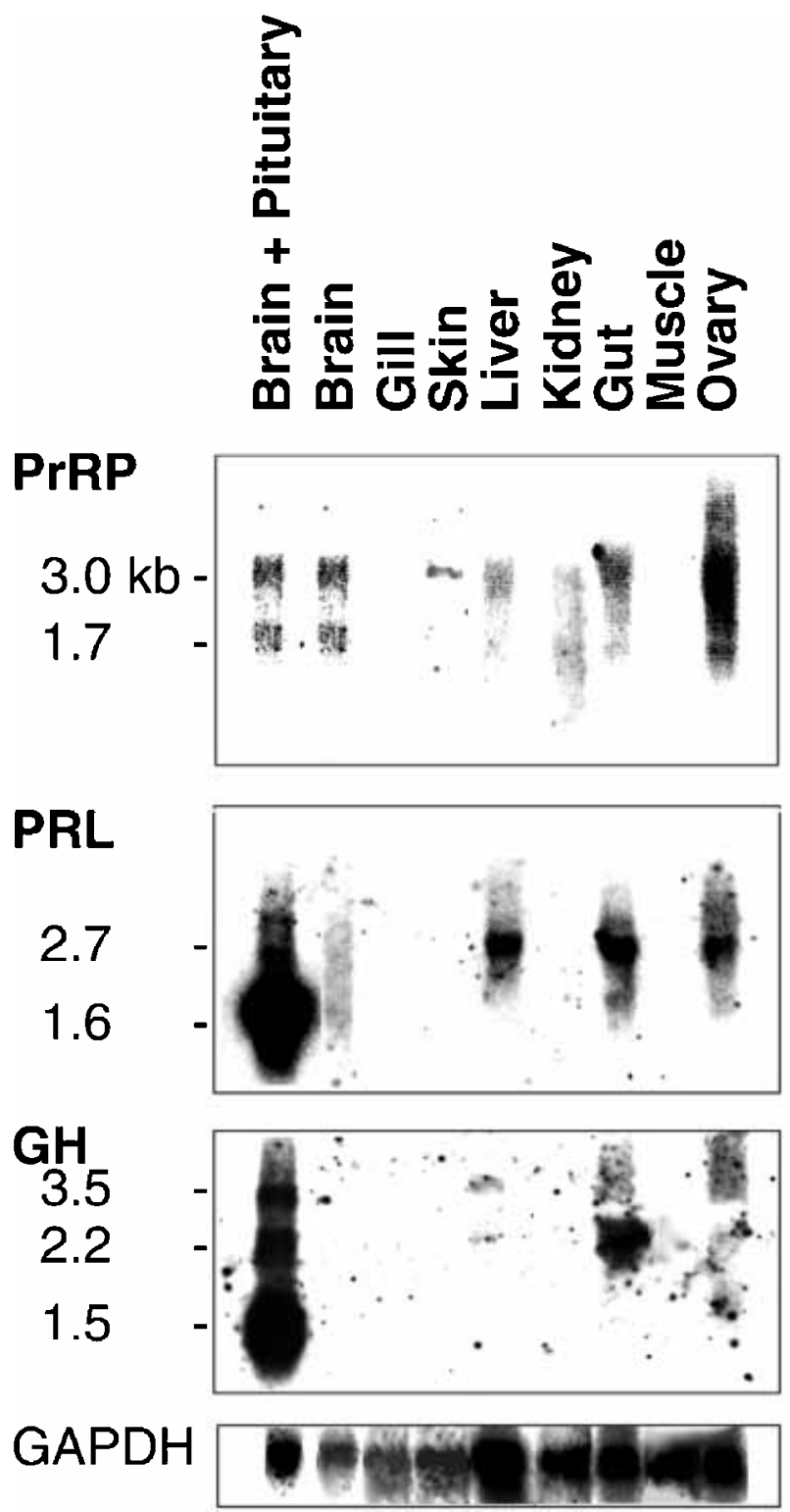

Figure 1 Northern-blot analyses for mudskipper mRNAs of PrRP, PRL and GH. Poly(A)+ RNA preparations obtained from the indicated tissues pooled from five fish were electrophoresed, transferred to a filter and then hybridized with $\left[\alpha-{ }^{32} \mathrm{P}\right] \mathrm{dCTP}-\mathrm{labelled} \mathrm{cDNA}$ of mudskipper PrRP. The membranes were rehybridized with cDNAs of mudskipper PRL, $\mathrm{GH}$ or GAPDH. Sizes of transcripts are indicated.

(Fig. 1), while signals were also observed in the skin and kidney. As for PRL mRNA, the apparent positive signals at about $2.7 \mathrm{~kb}$ were detected in the liver, gut and ovary, in addition to the highest level of expression in the pituitary (about 1.6 and $2.7 \mathrm{~kb}$ ). We could also detect signals for extrapituitary $\mathrm{GH}$ transcripts $(2 \cdot 2$ and $3.5 \mathrm{~kb})$ in the liver, gut and ovary, in addition to the highest pituitary level $(1 \cdot 5,2 \cdot 2$ and $3 \cdot 5 \mathrm{~kb})$. The low levels of the 


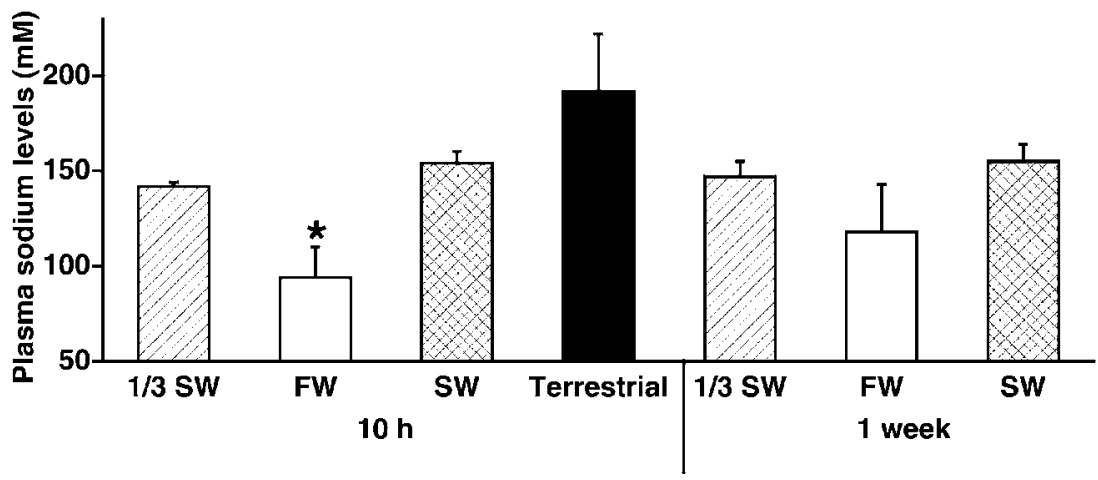

Figure 2 Plasma sodium concentrations in mudskipper under various environmental conditions and control (one-third sea water) for $10 \mathrm{~h}$ and 1 week. Values are means \pm S.E.M. $(n=4-6)$. For each time period, different letters above bars indicate a significant difference $(P<0.05$ versus control). SW, sea water; FW, fresh water.

extrapituitary signal were not due to blood-cell contamination, as no significant amount of RNA was extracted from blood.

\section{Expression of PrRP, PRL and GH mRNAs during environmental adaptation}

When mudskipper were transferred to fresh water, the plasma sodium levels decreased significantly after $10 \mathrm{~h}$ $(P<0 \cdot 05)$, and returned to a similar level to that in one-third sea water after 1 week. There was no significant difference in plasma sodium during adaptation to other environments, although a $20 \%$ increase was observed in fish kept out of water (Fig. 2).

In the brain (Fig. 3), PrRP mRNA levels increased under terrestrial conditions $(P<0 \cdot 05)$. After 1 week, the brain PrRP mRNA in freshwater fish was higher than that in sea-water fish $(P<0 \cdot 05)$. PRL mRNA levels in the pituitary increased after transfer to fresh water and the value of the 1-week group was significantly different $(P<0 \cdot 01)$. The pituitary PRL mRNA was also elevated under terrestrial conditions $(P<0 \cdot 05)$. On the other hand, GH mRNA levels in the pituitary increased progressively after sea-water transfer and the increase became significant after 1 week $(P<0 \cdot 05)$.

No significant change was seen in the liver mRNA levels either of PrRP, PRL or GH (Fig. 4). In the gut (Fig. 5), mRNA levels of both PrRP and PRL in freshwater fish were higher than those in sea-water fish and the levels of the 1-week group were significantly different $(P<0 \cdot 05)$. The gut GH mRNA increased 1 week after fresh-water transfer $(P<0 \cdot 05)$.

\section{PrRP-PRL localization in the intestine}

Figure 6A shows specific immunoreactive PrRP in the anterior intestine of freshwater-adapted mudskipper. Immunoreactive PrRP was observed in the epithelial cells, especially in the cytoplasm of mucous cells. Little immunoreactivity was found in the controls performed to validate the specificity of the immunoreaction (results not shown).

The localization of the PRL mRNA is shown in Fig. 6B. The hybridization signals were largely located in the PrRP-immunoreactive cells. Some signals were also detected in the lamina propria; however, these signals were differently coloured, not abolished by addition of an excess unlabelled probe, and these seem to be due to the autofluorescence of the blood cells (results not shown). No differences in the distribution of immunoreactive PrRP or signals for PRL mRNA were seen among the different samples.

\section{Discussion}

We have reported previously that PrRP promoted specifically PRL transcription and secretion, with the histochemical localization of PrRP neuronal terminals near PRL cells in the pituitaries of teleosts (Wang et al. 2000, Moriyama et al. 2002, Seale et al. 2002, Sakamoto et al. 2003b). In the present study, we demonstrated that PrRP and PRL expression are related both topographically and functionally in some organs of the mudskipper, a teleost, suggesting the possible presence of the PrRP-PRL axes in peripheral organs in addition to in the central nervous system.

The abundant expression of PrRP was observed in the brain, liver, gut and ovary in mudskipper, while less-abundant levels were also detected in the skin and kidney. In rat, PrRP mRNA expression was detected in the thyroid gland, trachea, submandibular gland, pancreas, gut, and reproductive organs in addition to the central nervous system. Among human peripheral tissues, the relatively high levels of PrRP mRNA were detected in the pancreas (Fujii et al. 1999). Although it is unknown whether the liver of mudskipper is a 


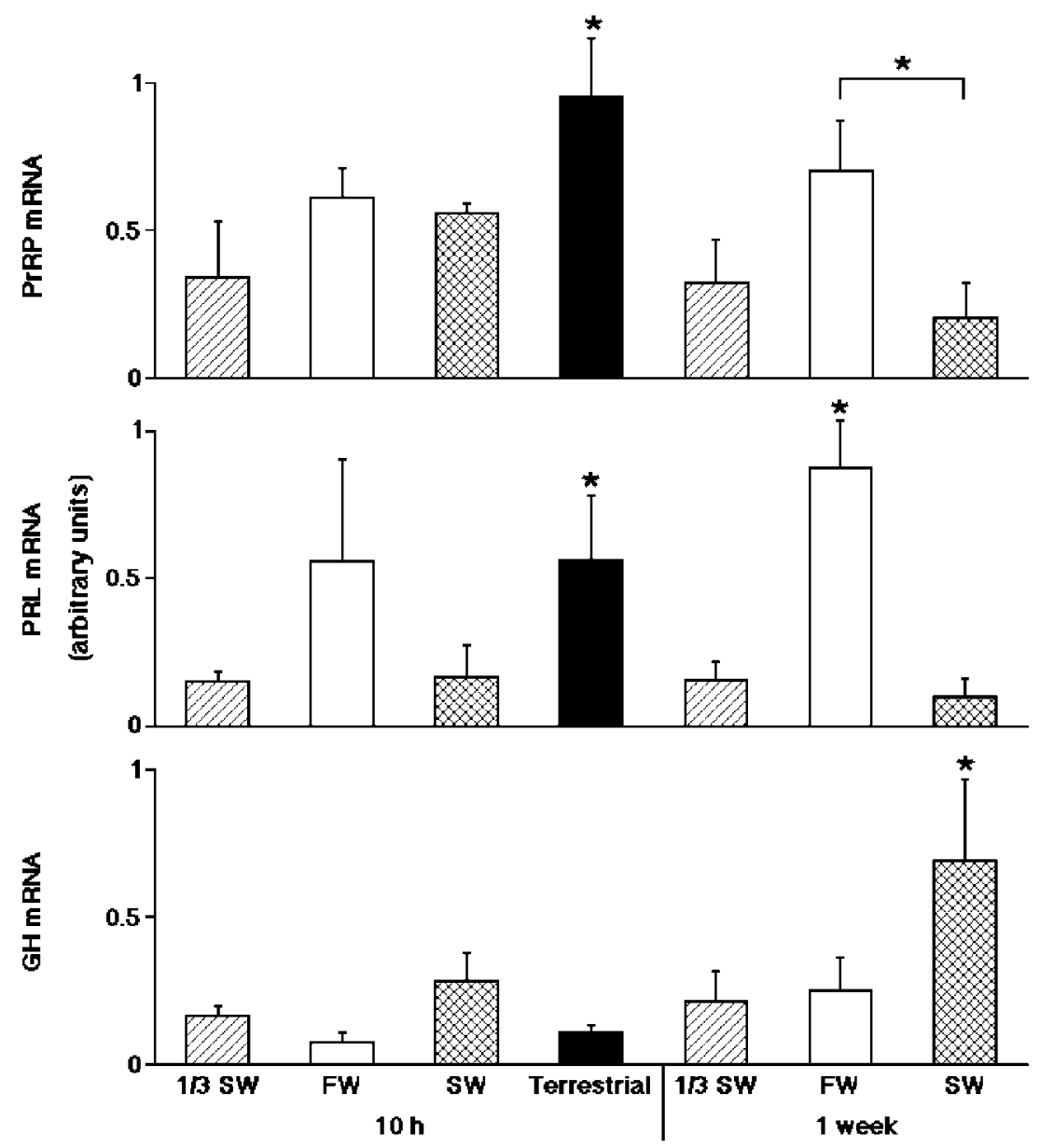

Figure 3 mRNA levels for PrRP in brain and for PRL and GH in pituitary from mudskipper under various environmental conditions and control (one-third sea water) for $10 \mathrm{~h}$ and 1 week. mRNA levels were examined by Northern blot (see Fig. 1). Values are means \pm S.E.M. and are expressed as arbitrary units $(n=4-6)$. For each time period, different letters above bars indicate a significant difference $(P<0.05$ versus control). SW, sea water; FW, fresh water.

hepatopancreas, the hybridization band in the liver may be due to the pancreatic tissues.

Corresponding to the distribution of PrRP mRNA in the mudskipper, relatively high expression of extrapituitary PRL mRNA was observed in the liver, gut and ovary. Since such high extrapituitary expression has been reported only in teleosts such as rainbow trout, goldfish and other perciforms (Santos et al. 1999, Yang et al. 1999, Imaoka et al. 2000), production of PRL might be centralized into pituitary during terrestrial tetrapod evolution. The larger size of extrapituitary PRL transcripts may reflect a difference of promoter usage as reported in mammalian lymphocytes and decidua, whose RNA transcripts are larger than the pituitary counterpart (Ben-Jonathan et al. 1996). GH gene expression was also detectable in these organs as in salmonid fishes (Yang et al. 1999).
During adaptation of the mudskipper to different environments, the changes in mRNA levels of PrRP and PRL paralleled in the brain-pituitary, liver, and gut. PrRP mRNA in the brain and the pituitary PRL mRNA increased under $10 \mathrm{~h}$ terrestrial conditions, indicating the activation of the brain-pituitary axis of PrRP-PRL during terrestrial adaptation and perhaps the relative importance of the pituitary PRL in terrestrial vertebrates. The increased plasma levels of sodium/ osmolality and cortisol during terrestrial adaptation (Sakamoto et al. 2002; Fig. 2) have been known to suppress PRL expression in teleosts (Sakamoto et al. 2003a). Under terrestrial conditions, the brain PrRP seems to importantly induce pituitary PRL. The induced pituitary PRL, as circulating PRL, may stimulate a preference for an aquatic habitat as observed in some amphibians. Indeed, when Xenopus was kept out of the 


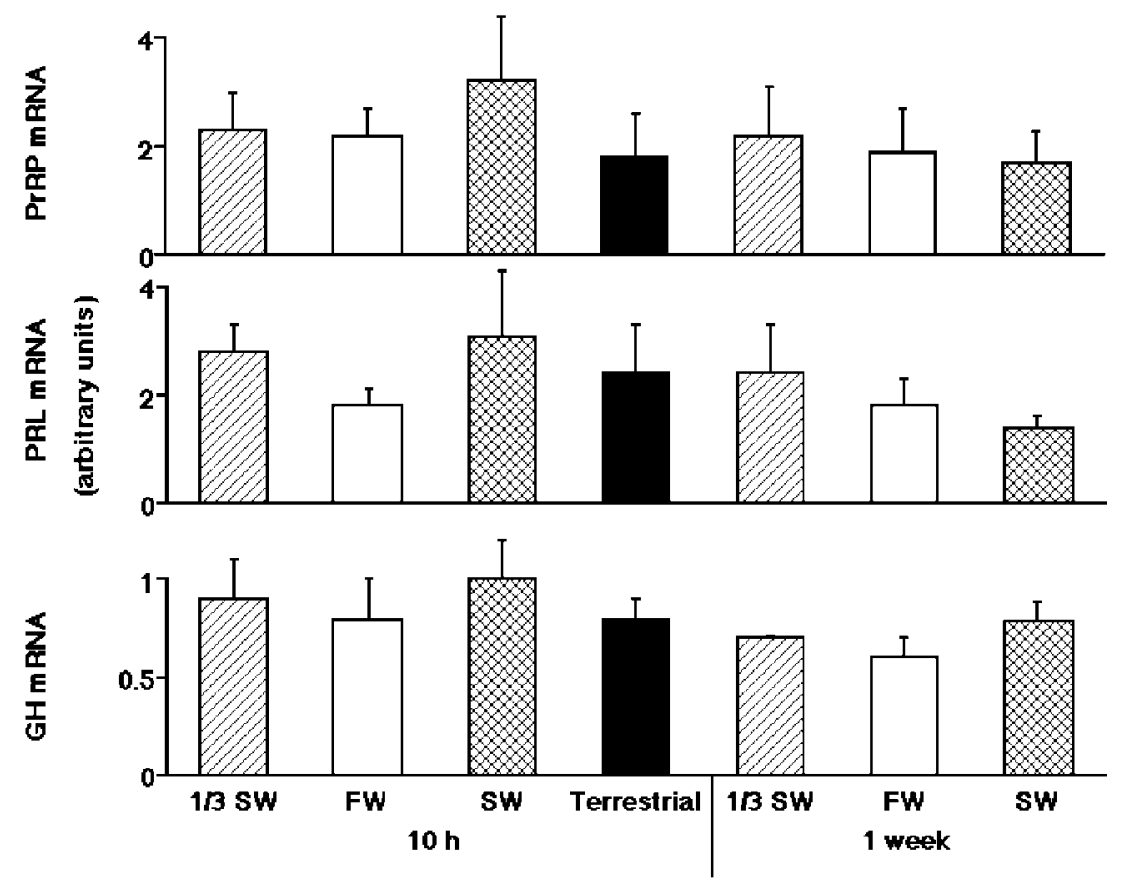

Figure 4 mRNA levels for PrRP, PRL and GH in liver from mudskipper under various environmental conditions and control (one-third sea water) for $10 \mathrm{~h}$ and 1 week. mRNA levels were examined by Northern blot (see Fig. 1). The $3.0 \mathrm{~kb}$ PrRP mRNA, $2.7 \mathrm{~kb}$ PRL mRNA and 3.5 and $2.2 \mathrm{~kb}$ GH mRNAs were analyzed, since the nature of other additional mRNAs was uncertain. Values are means \pm S.E.M. and are expressed as arbitrary units $(n=4-6)$. For each time period, no significant difference was seen $P>0.05)$. SW, sea water; FW, fresh water.

water PRL was synthesized (Warburg 1995). The brain PrRP and pituitary PRL mRNAs increased after 1 week in fresh water as well, demonstrating that the brain-pituitary axis also operates in fresh water. The pituitary PRL may decrease the integumental permeability in order to maintain the electrolytes in fresh water and the water in terrestrial environment. We have shown that the tissue resistance in the chloride-secreting skin of mudskipper increased during fresh-water adaptation and terrestrial adaptation, although chloride secretion diminished only during fresh-water adaptation (Sakamoto et al. 2000b). Actually, the primary action of PRL has been suggested to be the reduction in ion and water permeability of osmoregulatory surfaces without affecting their ion-transporting capacities (Hirano 1986). On the other hand, GH mRNA levels in the pituitary were elevated 1 week after sea-water transfer, consistent with the indirect inhibition of pituitary GH expression by brain PrRP (Sakamoto et al. 2003a). A sea-wateradapting action of $\mathrm{GH}$ in mudskippers appears to be similar to that reported in several teleosts such as salmonids, tilapia and killifish (Sakamoto et al. 1993, 1997, 2001).

Expressions of PrRP and PRL in the gut of freshwater fish were higher than those in sea-water fish after
1 week, although there was no change in fish kept out of water. Therefore, the axis in the gut operates specifically during fresh-water adaptation. In the gut, PrRP and PRL seem to be co-localized in the intestinal epithelia, especially in the mucus cells, contrary to the presence of PrRP mRNA in the lamina propria and the effects of PrRP on motor function in rat intestines (Roland et al. 1999, Grabauskas et al. 2004). In the intestinal epithelia, PrRP may stimulate PRL expression in an autocrine manner as observed in human dicidua (Reis et al. 2002). The induction of intestinal PRL in fresh water may have relevant implications. Specifically during fresh-water adaptation, intestinal PRL may participate locally in the epithelial (mucus) cell growth and/or in the inhibition of apoptosis, since the gut mucus cells are numerous in fresh-water fish, but not in sea-water fish (Yamamoto \& Hirano 1978). A large number of PRL's actions are associated with cell proliferation and/or apoptosis, and PRL has been shown to induce the hypertrophy of the intestinal mucosa in birds and mammals as well as the mucous cell size and number in fish gills (Bole-Feysot et al. 1998, Sakamoto et al. 2005). In the intestinal mucus cells of tilapia, PRL receptor mRNA has been clearly observed (Sandra et al. 2000). PrRP has also been suggested to promote growth and survival of 


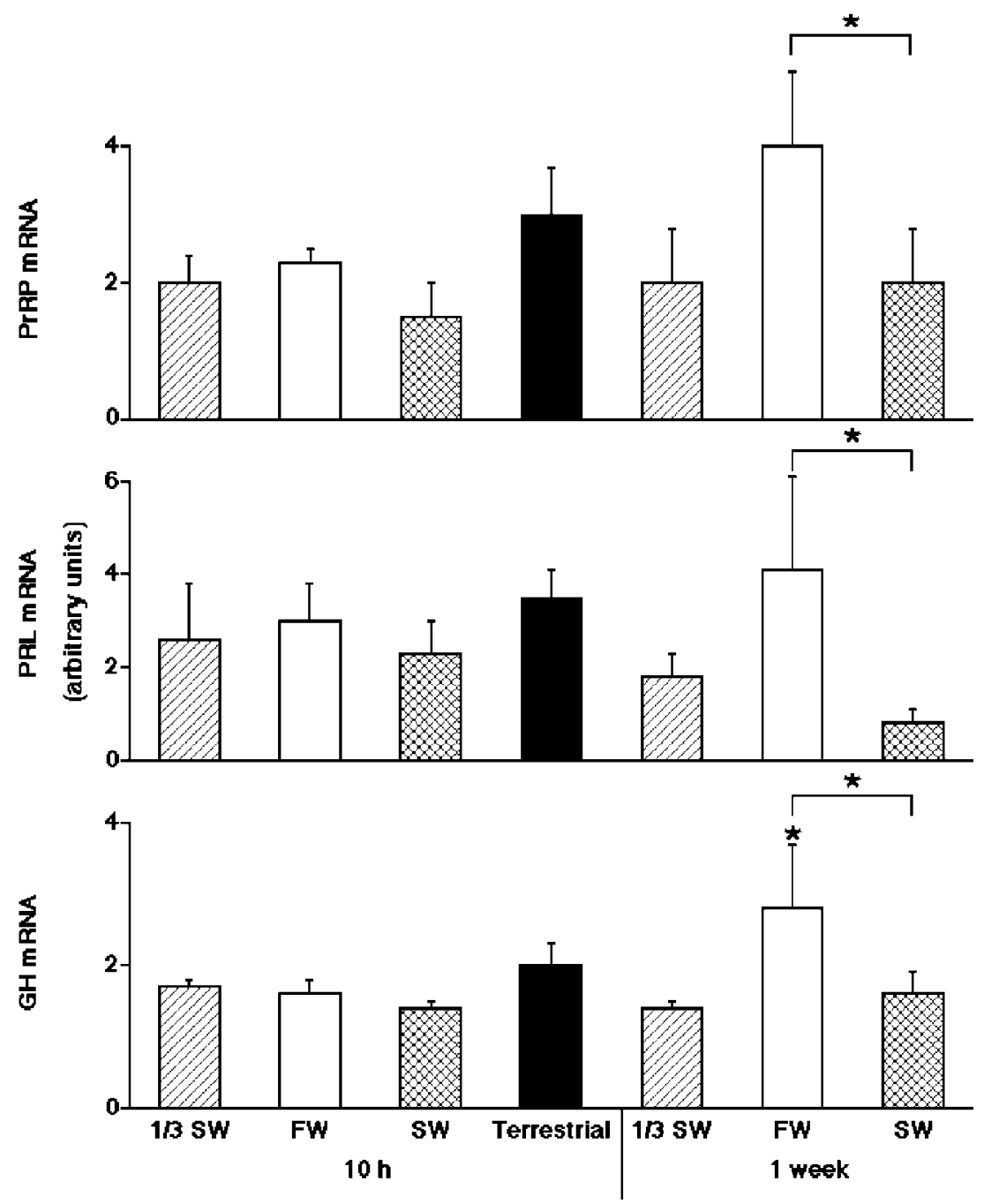

Figure 5 mRNA levels for PrRP, PRL and GH in gut from mudskipper under various environmental conditions and control (one-third sea water) for $10 \mathrm{~h}$ and 1 week. mRNA levels were examined by Northern blot (see Fig. 1) and analyzed as described for Fig. 4. Values are means \pm S.E.M. and are expressed as arbitrary units $(n=4-6)$. For each time period, different letters above bars indicate a significant difference $(P<0.05$ versus control). SW, sea water; FW, fresh water.

PRL-producing cells (Duval \& Gutierrez-Hartmann 2002), i.e. the mucus cells in the intestine. Furthermore, the increased expression of gut GH in fresh water may also be involved in the growth and differentiation of particular cells.

In the liver, no significant change was seen in PrRP, PRL or GH, suggesting their minor role during adaptation to different environments. The variation among organs may reflect the functional versatility of PrRP-PRL axis (Hirano 1986, Sakamoto et al. 2003a). Future studies should determine the effect of PrRP in the control of extrapituitary PRL production using the neutralizing antibodies or antisense oligonucleotides possibly with in vitro preparations.

In conclusion, we have shown that PrRP and PRL are co-expressed in some organs in a teleost during adaptation to different environments, suggesting that PrRP regulates PRL expression at the peripheral organs as well as at the pituitary. The possible presence of PrRP-PRL axes in the peripheral organs adds a new candidate for a specific local modulator of extrapituitary PRL, suggesting an ancient history of this axis prior to the evolution of the hypothalamus-pituitary. PrRP might be an original, fundamental regulator of PRL. 

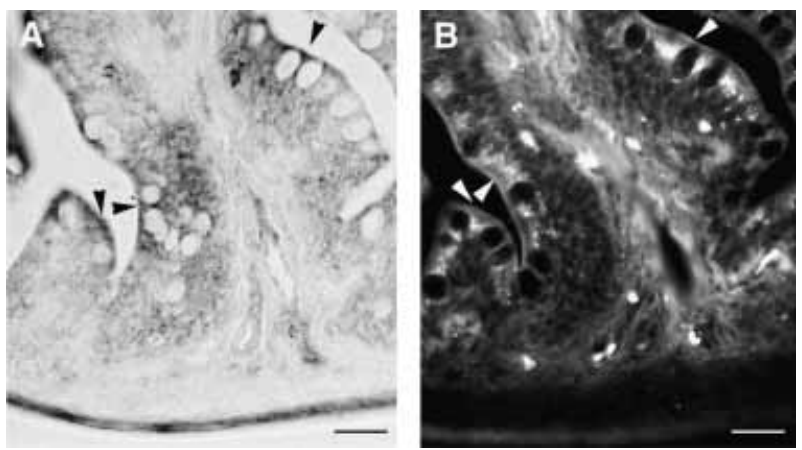

Figure 6 Cellular localization of PrRP-PRL in fresh-water mudskipper intestine. PrRP immunostaining is present in the epithelium, primarily in the cytoplasma of mucus cells $(A$; arrowhead). PRL mRNA is also expressed in the mucus cells by in situ bybridization (B; arrowhead). Scale bars, $10 \mu \mathrm{m}$.

\section{Acknowledgements}

We are indebted to $\mathrm{Dr} \mathrm{T}$. Agustsson and $\mathrm{Mr} \mathrm{H}$. Yasunaga for their help. This research was supported in part by Narishige Zoological Science Award and grants-in-aid for scientific research from the Society for the Promotion of Science, the Ministry of Education, and Fisheries Agency, Japan. We thank Professor Christopher A. Loretz for critical reading of the manuscript. The authors declare that there is no conflict of interest that would prejudice the impartiality of this scientific work.

\section{References}

Ben-Jonathan N, Mershon JL, Allen DL \& Steinmetz RW 1996 Extrapituitary prolactin: distribution, regulation, functions, and clinical aspects. Endocrine Reviews 17 639-669.

Bole-Feysot C, Goffin V, Edery M, Binart N, \& Kelly PA 1998 Prolactin (PRL) and its receptor: actions, signal transduction pathways and phenotypes observed in PRL receptor knockout mice. Endocrine Reviews 19 225-268.

Chomczynski P \& Sacchi N 1987 Single-step method of RNA isolation by acid guanidinium thiocyanate-phenol-chlorophorm extraction. Analytical Biochemistry 162 156-159.

Duval DL \& Gutierrez-Hartmann A 2002 PRL-releasing peptide stimulation of PRL gene transcription-enter AKT. Endocrinology $14311-12$.

Fujii R, Fukusumi S, Hosoya M, Kawamata Y, Habata Y, Hinuma S, Sekiguchi M, Kitada C, Kurokawa T, Nishimura O et al. 1999 Tissue distribution of prolactin-releasing peptide (PrRP) and its receptor. Regulatory Peptides $831-10$.

Fujimoto M, Takeshita K, Wang X, Takabatake I, Fujisawa Y, Teranishi H, Ohtani M, Muneoka Y \& Ohta S 1998 Isolation and characterization of a novel bioactive peptide, Carassius $\mathrm{RF}$-amide (C-RFa), from the brain of the Japanese crucian carp. Biochemical and Biophysical Research Communications 242 436-440.

Goffin V, Binart N, Touraine P \& Kelly PA 2002 Prolactin: the new biology of an old hormone. Annual Review of Physiology 64 47-67.

Gordon MS, Ng WWS \& Yip AYW 1978 Aspect of the physiology of terrestrial life in amphibious fishes. Fournal of Experimental Biology $7257-75$.
Grabauskas G, Zhou SY, Das S, Lu Y, Owyang C \& Moises HC 2004 Prolactin-releasing peptide affects gastric motor function in rat by modulating synaptic transmission in the dorsal vagal complex. Fournal of Physiology 561 821-839.

Hinuma S, Habata Y, Fujii R, Kawamata Y, Hosoya M, Fukusumi S, Kitada C, Masuo Y, Asano T, Matsumoto H et al. 1998 A prolactin-releasing peptide in the brain. Nature 393 272-276.

Hirano T 1986 The spectrum of prolactin action in teleosts. Progress in Clinical and Biological Research 205 53-74.

Hyodo S \& Urano A 1991 Changes in expression of provasotocin and proisotocin genes during adaptation to hyper- and hypo-osmotic environments in rainbow trout. Fournal of Comparative Physiology B $\mathbf{1 6 1} 549-556$.

Imaoka T, Matsuda M \& Mori T 2000 Extrapituitary expression of the prolactin gene in the goldfish, African clawed frog and mouse. Zoological Science 17 791-796.

Lee CGL \& Ip YK $1987 \mathrm{Na}+, \mathrm{K}+$ and volume regulation in the mudskipper Periophthalmus chrysospilos. Comparative Biochemistry and Physiology A $\mathbf{8 7} 439-448$.

Moriyama S, Ito T, Takahashi T, Amano M, Sower SA, Hirano T, Yamamori K \& Kawauchi H 2002 A homologue of mammalian prolactin-releasing peptide (fish arginyl-phenylalanyl-amide peptide) is a major hypothalamic peptide of prolactin release in teleost fish. Endocrinology 143 2071-2079.

Rand-Weaver M, Kawauchi H \& Ono M 1993 Evolution of the structure of the growth hormone and prolactin family. In The Endocrinology of Growth, Development, and Metabolism in Vertebrates, pp 13-42. Eds MP Schreibman, CG Scanes \& PKT Pang. New York: Academic Press.

Reis FM, Vigano P, Arnaboldi E, Spritzer PM, Petraglia F \& Di Blasio AM 2002 Expression of prolactin-releasing peptide and its receptor in the human decidua. Molecular Human Reproduction 8 356-362.

Roland BL, Sutton SW, Wilson SJ, Luo L, Pyati J, Huvar R, Erlander MG \& Lovenberg TW 1999 Anatomical distribution of prolactin-releasing peptide and its receptor suggests additional functions in the central nervous system and periphery. Endocrinology $1405736-5745$.

Sakamoto T, McCormick SD \& Hirano T 1993 Osmoregulatory actions of growth hormone and its mode of action in salmonids: A review. Fish Physiology and Biochemistry 11 155-164.

Sakamoto T, Shepherd BS, Madsen SS, Nishioka RS, Siharath K, Richman NHI, Grau EG \& Bern HA 1997 Osmoregulatory actions of growth hormone and prolactin in an advanced teleost. General and Comparative Endocrinology 106 95-101.

Sakamoto T, Yokota S \& Ando M 2000a Rapid morphological oscillation of mitochondrion-rich cell in estuarine mudskipper following salinity changes. Fournal of Experimental Zoology $\mathbf{2 8 6}$ 666-669.

Sakamoto T, Agustsson T, Björnsson BTh \& Ando M $2000 b$ Roles of growth hormone and prolactin during adaptation of the gobies to various environments. In Growth and Growth Regulation in Fish, pp 29-32. Eds Th Bjornsson \& D MacKinlay. Vancouver: American Fisheries Society.

Sakamoto T, Uchida K \& Yokota S 2001 Regulation of the ion-transporting mitochondrion-rich cell during adaptation of teleost fishes to different salinities. Zoological Science $\mathbf{1 8}$ $1163-1174$.

Sakamoto T, Yasunaga H, Yokota S \& Ando M 2002 Differential display of skin mRNAs regulated during adaptation of mudskipper to different environments. Fournal of Comparative Physiology B 172 $447-453$.

Sakamoto T, Fujimoto M \& Ando M 2003a Fishy tales of prolactin-releasing peptide. International Review of Cytology 225 91-130.

Sakamoto T, Agustsson T, Moriyama S, Takahashi A, Kawauchi H, Björnsson BTh \& Ando M $2003 b$ Intraarterial injection of prolactin-releasing peptide elevates prolactin gene expression and 
plasma prolactin levels in rainbow trout. Fournal of Comparative Physiology B 173 333-337.

Sakamoto T, Oda A, Narita K, Takahashi H, Oda T, Fujiwara J \& Godo W 2005 Prolactin: fishy tales of its primary regulator and function. Annals of the New York Academy of Sciences (in press).

Sambrook J, Fritcsh EF \& Maniatis T 1989 Molecular Cloning: a Laboratory Manual with the Laboratory Manual Source Book. Cold Spring Harbor: Cold Spring Harbor Press.

Sandra O, Le Rouzic P, Cauty C, Edery M \& Prunet P 2000 Expression of the prolactin receptor (tiPRL-R) gene in tilapia Oreochromis niloticus: tissue distribution and cellular localization in osmoregulatory organs. Fournal of Molecular Endocrinology 24 215-224.

Santos CR, Ingleton PM \& Power DM 1999 Cloning, characterization, and tissue distribution of prolactin receptor in the sea bream (Sparus aurata). General and Comparative Endocrinology $11457-66$.

Seale AP, Itoh T, Moriyama S, Takahashi A, Kawauchi H, Sakamoto T, Fujimoto M, Riley LG, Hirano T \& Grau EG 2002 Isolation and characterization of a homologue of mammalian prolactin-releasing peptide from the tilapia brain and its effect on prolactin release from the tilapia pituitary. General and Comparative Endocrinology 125 328-339.

Wang X, Morishita F, Matsushima O \& Fujimoto M 2000 Immunohistochemical localization of C-RFamide, a FMRF-related peptide, in the brain of the goldfish, Carassius auratus. Zoological Science 17 1067-1074.

Warburg MR 1995 Hormonal effect on the osmotic, electrolyte and nitrogen balance in terrestrial Amphibia. Zoological Science 12 $1-11$.

Yamamoto M \& Hirano T 1978 Morphological changes in the esophageal epithelium of the eel, Anguilla japonica, during adaptation to seawater. Cell Tissue Research 192 25-38.

Yang BY, Greene M \& Chen TT. 1999 Early embryonic expression of the growth hormone family protein genes in the developing rainbow trout, Oncorhynchus mykiss. Molecular Reproduction and Development 53 127-134.

Received 21 February 2005

Accepted 28 February 2005

Made available online as an Accepted Preprint 8 March 2005 